\title{
MicroRNA-182 targets FOXF2 to promote the development of triple-negative breast cancer
}

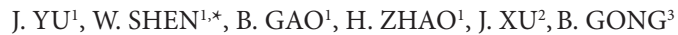

${ }^{1}$ Department of Breast Surgery, ${ }^{2}$ Department of Pathology, ${ }^{3}$ Department of Laboratory, Shanghai Changning Maternity \& Infant Health Hospital, Shanghai, China, 200051

*Correspondence: shenweidaswd123@sina.com

Received July 18, 2016/ Accepted October 21, 2016

\begin{abstract}
To explore the function of microRNA-182 (miR-182) on MCF7 and MDA-MB-231 cells behaviors, and possible mechanisms of triple-negative breast cancer (TNBC) development. Totally, 30 TNBC patients were enrolled to investigate the correlation between miR-182 expression and TNBC clinical indicators. miR-182 expression in TNBC tissues was measured by qRT-PCR, followed by bioinformatics methods and luciferase reporter assay to investigate whether FOXF2 was a direct target of miR182. Besides, miR-182 mimics were transfected into MCF7 cells while miR-182 inhibitor into MDA-MB-231 cells, followed by cell proliferation and migration detection. miR-182 expression was significantly correlated with TNBC clinical indicators, such as lymph node metastasis TNM (stage III), intravascular cancer emboli and TNBC recurrence and metastasis. miR-182 expression was significantly higher in TNBC tissues than that in matched normal tissues, and was significantly higher in MDA-MB-231 cells than that in MCF7 cells. miR-182 knockdown inhibited the proliferation and migration of MDA-MB-231 cells while miR-182 overexpression markedly promoted the proliferation and migration of MCF7 cells. Besides, FOXF2 was identified as a direct target of miR-182. Our findings indicate that miR-182 may promote cell proliferation and migration in TNBC possible via down-regulation of FOXF2. miR-182 may serve as a potential target in TNBC treatment.
\end{abstract}

Key words: triple-negative breast cancer, microRNA-182, FOXF2, proliferation, migration

Triple-negative breast cancer (TNBC) is an aggressive disease, accounting for approximately $12 \%-24 \%$ of all breast cancer cases [1]. It is defined immunohistochemically by absence of expression of progesterone receptor (PR), estrogen receptor (ER) and human epidermal growth factor receptor 2 (HER2, ERBB2) [2,3]. Due to lack of effective targeted therapies to date, treatment regimens for TNBC often fail to slow down the progression of tumor [4]. Therefore, more efforts are still warranted to elucidate the molecular mechanisms underlying TNBC.

MicroRNAs (miRNAs) are emerging as key regulators in some physiological and pathological processes via targeting the 3' UTRs of specific target mRNAs at the post-transcriptional level $[5,6]$. miRNAs can act as oncogenes or tumor suppressors in the progression of a variety of prevalent cancers $[7,8]$, including TNBC [9]. For instance, upregulated miRNA-155 contributes to lymph node metastasis and is associated with poor prognosis in TNBC [10]. Upregulated miR-203 is also observed to suppress TNBC cell proliferation and migration
[11]. Recently, accumulating evidences have highlighted the key regulatory roles of miR-182 in cancer progression and patients' survival. The aberrant expression and crucial function of miR-182 are increasingly disclosed in several cancers, including melanoma [12], glioma [13], lung cancer [14] and breast cancer [15]. It can therefore be hypothesized that miR-182 may be widely implicated in tumor development. However, the function of miR-182 in breast cancer has not been fully investigated, especially in TNBC.

In this study, the correlation between miR-182 expression and TNBC clinical indicators was investigated. miR-182 expression in TNBC tissues, MCF-7 and MDA-MB-231 cells were then measured. In addition, we investigated whether FOXF2 was a direct target of miR-182. Besides, miR-182 mimics were transfected into MCF7 cells while miR-182 inhibitor was transfected into MDA-MB-231 cells to further detect the effects of miR-182 on cell proliferation and migration. Our study aimed to determine the function of miR-182 on the malignant behaviors of MCF7 and MDA-MB-231 cells, 
as well as to elucidate the possible mechanisms of TNBC development. Findings of this study will help to devise possible targets for TNBC.

\section{Materials and methods}

Samples collection. Our study was reviewed and approved by the local ethics committee and each patient provided informed consent. Between January 2009 and January 2013, a total of 30 TNBC patients (aged 31-73 years, mean 51.1 years) were enrolled in our study. All patients were confirmed by histopathology, did not receive preoperative radiotherapy or chemotherapy, and underwent postoperative adjuvant chemotherapy with TAC (pirarubicin + cyclophosphamide + docetaxel). Then 30 TNBC tissues and 30 matched normal tissues from these patients were collected and quickly snap-frozen for subsequent experiments.

Cell culture and transfection. Human breast cancer cell lines MCF-7 (low metastatic potential) and MDA-MB231 (high metastatic potential) were obtained from the Animal Experiment Center of Shanghai, Chinese Academy of Sciences. Cells were seeded into DMEM medium (Gibco, NY, USA) supplement with $10 \%$ FBS and $1 \%$ penicillin/ streptomycin at $37^{\circ} \mathrm{C}$ in an incubator with $5 \% \mathrm{CO}_{2}$. Cells $\left(5 \times 10^{5}\right)$ were then seeded in 6 -well plates. Then miR-182 mimics were transfected into MCF7 cells while miR-182 inhibitor was transfected into MDA-MB-231 cells with lipofectamine RNAiMAX Reagent (Invitrogen, CA, USA) based on manufacturer's instruction. MicroRNA NC and microRNA inhibitor NC were also respectively transfected into MCF-7 and MDA-MB-231cells as the negative controls. The sequences were as follows: miR-182 mimics: forward, 5'-UUUGGCAAUGGUAGAACUCACACU-3'; reverse: 5'-UGUGAGUUCUACCAUUGCCAAAUU-3'; MicroRNA NC, forward, 5'-UUCUCCGAACGUGUCACGUTT-3'; reverse, 5'-ACGUGACACGUUCGGAGAATTA-3'; miR-182 inhibitor, 5'-AGUGUGAGUUCUACCAUUGCCAAA-3'; microRNA inhibitor NC, 5'-AGUGUGAGUUCUACCAUUGCCAAA-3'. After transfection, miR182 expression was measured by quantitative real-time PCR (qRT-PCR) to detect the transfection efficiency.

Bioinformatic methods and luciferace reporter assay. The miRNA targets were predicted by Targetscan (http://www. targetscan. org/vert_61/). FOXF2 at position 688-695 and 485491 was found as the potential target regions of miR-182. To further confirm which target region of FOXF2 was the target of miR-182, a luciferase reporter assay was conducted with the Luciferase Reporter Assay System (Promega, Wisconsin, USA). In brief, MCF7 cells were cultured in 48-well plates for incubation of $24 \mathrm{~h}$, and then co-transfected with pGL3 vector (Promega, Wisconsin, USA) containing miR-128 binding site of FOXF2 3'UTR (WT) or deleting the sequence of binding site (MUT) with or without miR-128 mimics. At $48 \mathrm{~h}$ after incubation, the luciferase activity was measured by a microplate reader (Perkin-Elmer, CA, USA) and normalized to renilla luciferase activity.

RNA extraction and qRT-PCR. Trizol reagent (Invitrogen, CA, USA) was used to extract total RNA. The quality $\left(\mathrm{A}_{260} /\right.$ $\mathrm{A}_{280}$ ) and concentration of RNA was detected using SMA 400 UV-VIS (Merinton, Shanghai, China). cDNA synthesis was then performed by reverse transcription. qRT-PCR analysis was conducted with the SYBR ExScript qRT-PCR Kit (Takara, Dalian, China). The PCR conditions were: $95{ }^{\circ} \mathrm{C} 10 \mathrm{~min} ; 40$ cycles of $95{ }^{\circ} \mathrm{C} 15 \mathrm{sec}, 60^{\circ} \mathrm{C} 1 \mathrm{~min}$ and $72{ }^{\circ} \mathrm{C} 30 \mathrm{sec} ; 72{ }^{\circ} \mathrm{C} 5$ min. The expression of miR-182 and FOXF2 were normalized to U6 and GAPDH, respectively. The primers for gene amplification were: miR-182: forward, 5'-GGCTTTGGCAATGGTAGAAC-3', reverse, 5'-GTGCGTGTCGTGGAGTCG-3'; FOXF2: forward, 5'-GGATATTAAGCCCTGCGTCA-3', reverse: 5'-TTCAGATTGGGGAACGCTAC-3'; GAPDH: forward, 5'-CCCACTAACATCAAATGGGG-3', reverse: 5'- CCTTCCACAATGCCAAAGTT-3'. The relative gene expression was then calculated by the $2^{-\triangle \Delta C T}$ method.

Western blot. MCF7 cells were harvested after transfection with miR-182 mimics for $48 \mathrm{~h}$ and then lysed in RIPA lysis buffer. Equal amount of protein samples were separated on SDS-PAGE gel and electrophoretically transferred to a PVDF membrane (Millipore, MA, USA). The membranes were incubated with primary antibodies to FOFX2 and GAPDH (1:10000, Roche, Robert Rohrberg, Germany) overnight at $4^{\circ} \mathrm{C}$, followed by HRP-conjugated secondary goat anti-rabbit $\operatorname{IgG}(\mathrm{H}+\mathrm{L})(1: 5000$, Sigma, Taufkirchen, USA) or goat antimouse $\operatorname{IgG}(\mathrm{H}+\mathrm{L})(1: 10000$, Thermo, $\mathrm{CA}, \mathrm{USA})$ for $2 \mathrm{~h}$ at room temperature. Finally, the blots were visualized with electrochemi-luminescence (ECL) (Thermo, CA, USA).

Cell viability assay. Cell proliferation was evaluated with the Cell Counting Kit 8 (CCK-8, biosharp, hefei, China). In brief, cells (3000 cells/well) were seeded in 96-well plates. At 72 $\mathrm{h}$ after transfection, each well was changed to DEME medium containing $10 \%$ CCK- 8 solution and the plates continued to be incubated at $37^{\circ} \mathrm{C}$ for $1 \mathrm{~h}$. Absorbance $(450 \mathrm{~nm})$ of each well was measured with a microplate reader (Perkin-Elmer, CA, USA). All experiments were performed in triplicate.

Transwell assay. Cell migration assay was conducted using Transwell assay after $24 \mathrm{~h}$ of transfection. In brief, MDA-MB231 and MCF7 cells (40,000 cells in $100 \mu \mathrm{L}$ DEME medium without FBS) were added into the upper compartment of Transwell chamber (pore size $8.0 \mu \mathrm{m}, \mathrm{BD}$ Biosciences, CA, USA). The lower compartment was loaded with DEME medium containing $10 \%$ FBS as the nutritional attractant. After incubation for $24 \mathrm{~h}$, the chambers were fixed with $4 \%$ paraformaldehyde and then stained with DAPI. The cells on the upper side of the chamber were removed before observation. Five randomly fields on the bottom of the chamber were selected and the migrated cells were counted under an inversed fluorescent microscope $(20 \times$ magnification $)$.

Statistical analysis. Statistical differences between multiple results in our study were analyzed by SPSS 17.0. All data were presented as mean $\pm \mathrm{SD}$. The correlation between miR-182 

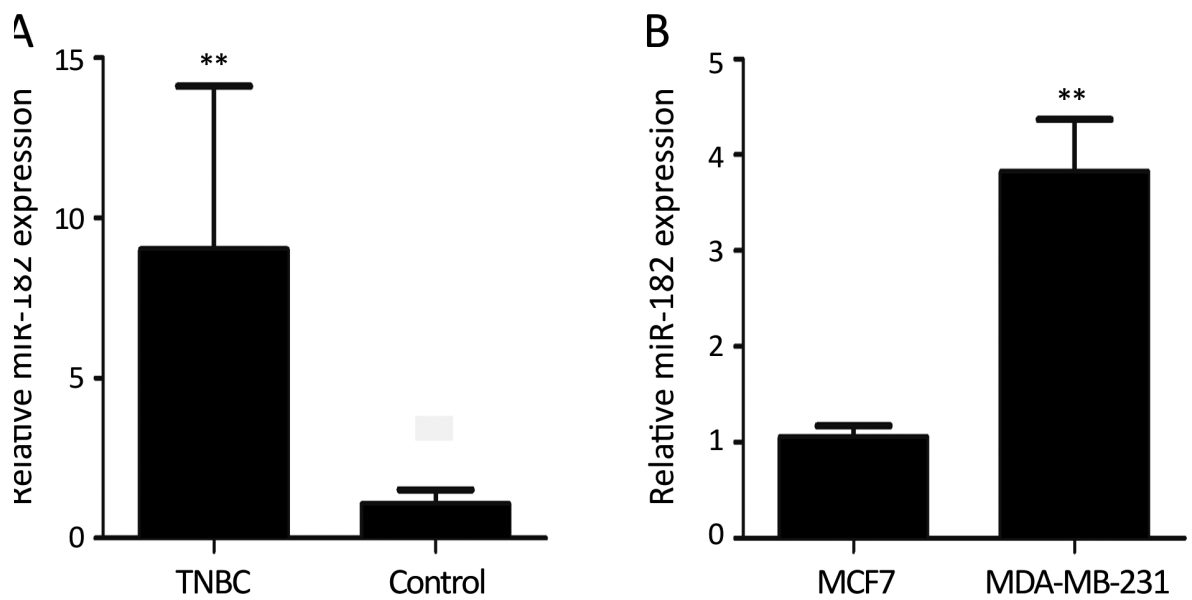

Figure 1. Analysis of the expression of miR-182 in TNBC tissues (A) and MDA-MB-231 and MCF7 cells (B). Data are presented as mean \pm SD. ${ }^{*}$ : $\mathrm{P}<0.05,{ }^{* *}: \mathrm{P}<0.01$.

expression and TNBC clinical indicators was evaluated by Mann Whitney-U test. The statistical differences in miR-182 expression, cell viability, cell migration between groups were assessed by paired t-test or one-way ANOVA. Statistically significant difference was obtained when $\mathrm{P}<0.05$.

\section{Results}

The correlation between miR-182 expression and TNBC clinical indicators. The correlation between miR-182 expression and TNBC clinical indicators was shown in Table 1. By Mann Whitney-U test, miR-182 expression in TNBC tissues with lymph node metastasis was significantly higher than that in TNBC tissues without lymph node metastasis $(\mathrm{Z}=$ -3.454, $\mathrm{P}=0.001$ ), was significantly higher in TNBC with TNM (stage III) than that in TNBC with TNM (stage I+II) (Z $=-3.946, \mathrm{P}=0.000$ ), and was also markedly higher in TNBC with intravascular cancer emboli than that in TNBC without emboli $(Z=-3.247, P=0.01)$. During the follow-up, significant differences in miR-182 expression still existed between TNBC with and without recurrence and metastasis $(Z=-2.408$, $\mathrm{P}=0.016)$. However, there were no significant differences in miR-182 expression between TNBC tissues withdifferent histological grades, tumor size, menstrual status and ki-67 index $(\mathrm{P}>0.05)$.

Analysis of miR-182 expression. The results of qRT-PCR showed that the expression of miR-182 in TNBC tissues was significantly higher than that in matched normal tissues $(\mathrm{P}<$ 0.01 , Figure $1 \mathrm{~A})$. In addition, the expression levels of miR-182 in MCF-7 and MDA-MB-231 cells were also measured. We found that miR-182 expression in MDA-MB-231 cells was markedly higher than that in MCF7 cells $(\mathrm{P}<0.01$, Figure 1B).

FOXF2 was a direct target of miR-182. In this study, Targetscan software predicted that FOXF2 at position 485-491 (U1) and 688-695 (U2) were the potential target regions of miR-182 (Figure 2A). In order to further verify the predicted results, FOXF2-U1 and FOXF2-U2 were co-transfected into MCF7 cells with miR-182 mimics, and the luciferase reporter assay was then performed to verify the predicted results. As

Table 1. The correlation between miR-182 expression and TNBC clinical indicators

\begin{tabular}{|c|c|c|c|c|}
\hline Clinical indicators & Cases & mean \pm SD & Z & $P$ value \\
\hline Histological type & & & -1.087 & 0.277 \\
\hline basaloid carcinoma & 11 & $9.568 \pm 5.569$ & & \\
\hline Others & 19 & $8.275 \pm 4.555$ & & \\
\hline Menstrual status & & & -0.733 & 0.464 \\
\hline premenopausal & 12 & $9.619 \pm 5.351$ & & \\
\hline postmenopausal & 18 & $8.090 \pm 4.805$ & & \\
\hline Histological grade & & & -0.326 & 0.745 \\
\hline $\mathrm{G} 1+\mathrm{G} 2$ & 15 & $9.436 \pm 4.750$ & & \\
\hline G3 & 15 & $8.579 \pm 5.581$ & & \\
\hline Lymph node metastasis & & & -3.454 & 0.001 \\
\hline negative & 17 & $6.945 \pm 3.791$ & & \\
\hline positive & 13 & $13.820 \pm 4.642$ & & \\
\hline Tumor size & & & -1.855 & 0.064 \\
\hline $\mathrm{PT} 1+2$ & 28 & $9.605 \pm 5.217$ & & \\
\hline $\mathrm{PT} 3+4$ & 2 & $5.985 \pm 1.959$ & & \\
\hline TNM staging & & & -3.946 & $<0.001$ \\
\hline $\mathrm{I}+\mathrm{II}$ & 24 & $7.133 \pm 3.669$ & & \\
\hline III & 6 & $15.169 \pm 4.375$ & & \\
\hline Ki-67 & & & -0.334 & 0.738 \\
\hline$\leq 14 \%$ & 25 & $9.374 \pm 4.598$ & & \\
\hline$\geq 14 \%$ & 5 & $8.687 \pm 5.652$ & & \\
\hline Intravascular cancer emboli & & & -.3 .247 & 0.001 \\
\hline no & 21 & $7.442 \pm 4.561$ & & \\
\hline yes & 9 & $13.313 \pm 4.114$ & & \\
\hline Recurrence and metastasis & & & -2.408 & 0.016 \\
\hline no & 25 & $7.388 \pm 3.304$ & & \\
\hline yes & 5 & $17.106 \pm 5.050$ & & \\
\hline
\end{tabular}


A

\begin{tabular}{l|cc}
$\begin{array}{c}\text { predicted consequential pairing of target } \\
\text { region (top) and miRNA (bottom) }\end{array}$ & \multicolumn{2}{c}{ seed match } \\
\hline $\begin{array}{l}\text { Position } 688-695 \text { of FOXF2 3' UTR } \\
\text { hsa-miR-182 }\end{array}$ & $5^{\prime}$ & . . GUAUACUUUUACAGUUUGCCAAA... \\
\hline
\end{tabular}

\begin{tabular}{|c|c|}
\hline $\begin{array}{l}\text { predicted consequential pairing of target } \\
\text { region (top) and miRNA (bottom) }\end{array}$ & seed match \\
\hline $\begin{array}{l}\text { Position } 485-491 \text { of FOXF2 } 3^{\prime} \text { UTR } \\
\text { hsa-miR-182 }\end{array}$ & 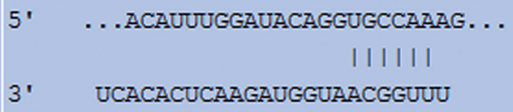 \\
\hline
\end{tabular}

B

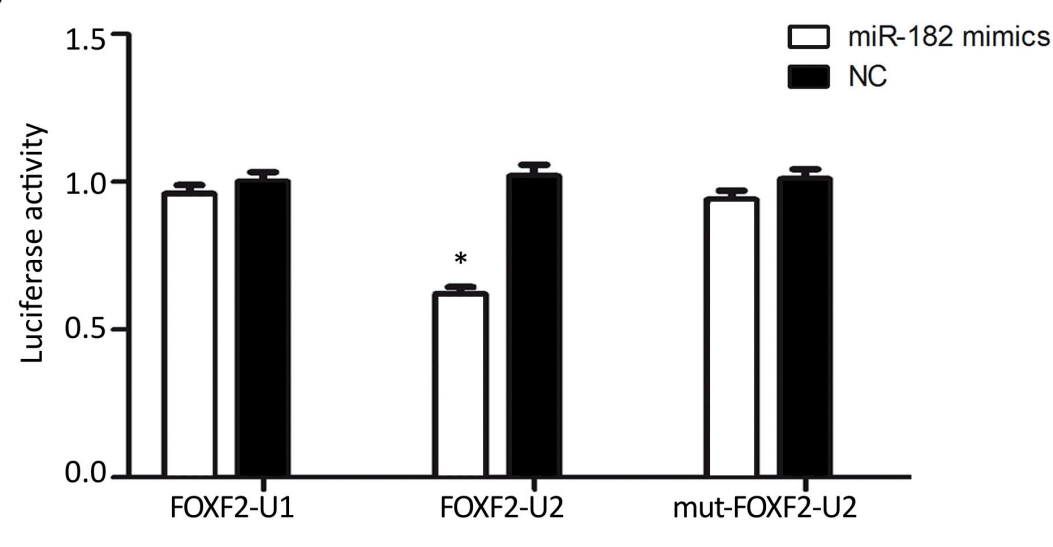

C

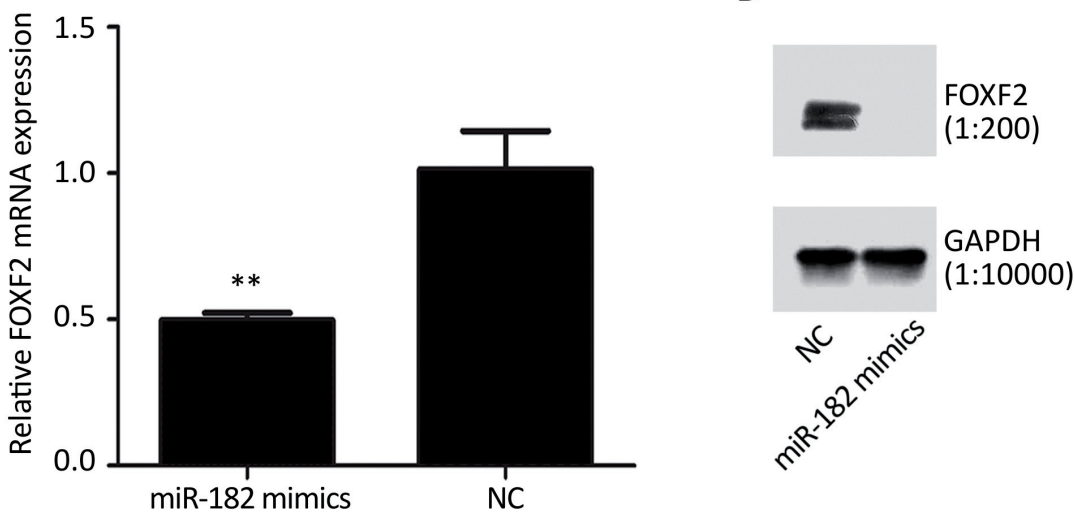

Figure 2. FOFX2 was a directly target of miR-182. A: the results of predicted analysis of Targetscan; B: the results of luciferase report assay; C: the expression of FOFX2 mRNA after miR-182 overexpression; D: the expression of FOFX2 protein after miR-182 overexpression. Data are presented as mean \pm SD. ${ }^{*}: \mathrm{P}<0.05,{ }^{* *}: \mathrm{P}<0.01$.

shown in Figure 2B, the luciferase activity of FOXF2-U2 was significantly decreased $(\mathrm{P}=0.001)$, while there was no obvious change in the luciferase activity of FOXF2-U1 $(\mathrm{P}=0.145)$. Besides, the results of qRT-PCR and western blot showed FOXF2 expression was significantly decreased in miR-182 mimics transfected MCF7 cells in comparison with control $(\mathrm{P}<0.05$, Figure $2 \mathrm{C}$ and $2 \mathrm{D})$. Taken together, these findings suggest that FOXF2 (688-695) is a target of miR-182.
Overexpression of miR-182 promoted cell proliferation and migration. miR-182 mimics were transfected into MCF7 cells while miR-182 inhibitor was transfected into MDA-MB-231 cells to further detect the function of miR182. The results of CCK- 8 assay showed that in comparison with negative control, miR-182 knockdown significantly inhibited the proliferation of MDA-MB-231 cells while miR182 overexpression markedly promoted the proliferation of 

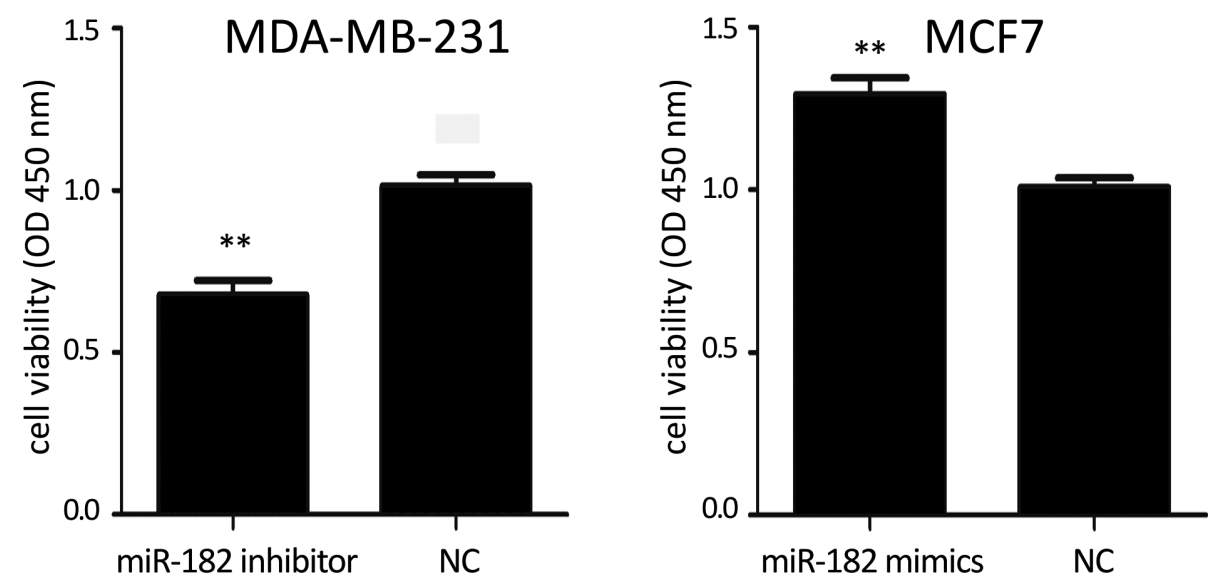

Figure 3. The cell viability of MCF7 cells and MDA-MB-231 cells after transfection with miR-182 mimics and miR-182 inhibitor, respectively. Data are presented as mean \pm SD. ${ }^{*}: \mathrm{P}<0.05,{ }^{* *}: \mathrm{P}<0.01$.

MCF7 cells $(P<0.01$, Figure 3). In addition, the miR-433 inhibitor transfected group had significantly fewer migrated MDA-MB-231cells than the control group, while the miR-

A

MDA-MB-231

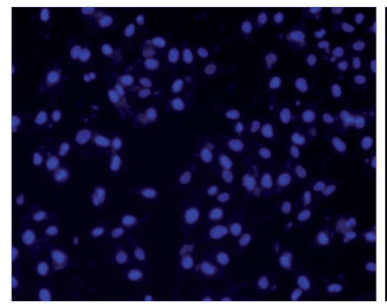

NC

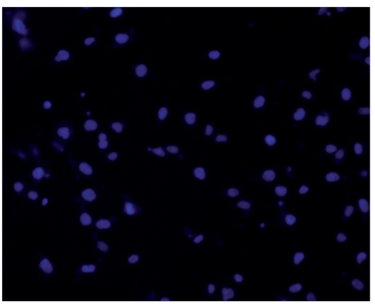

miR-182 inhibitor
433 mimics transfected group had obviously more migrated MDA-MB-231cells than the control group $(\mathrm{P}<0.05$, Figure 4A, 4B).

B

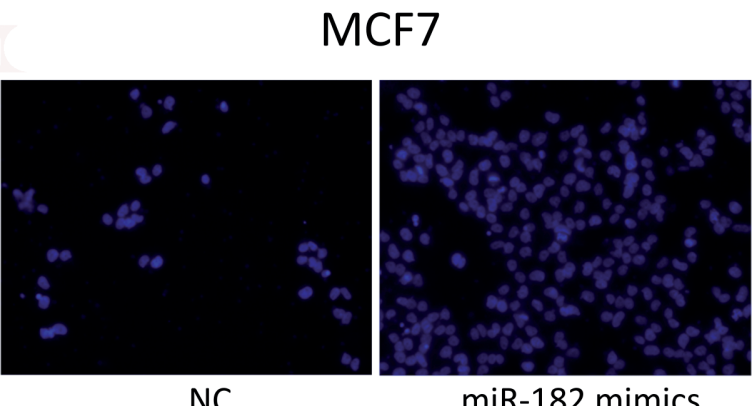

miR-182 mimics
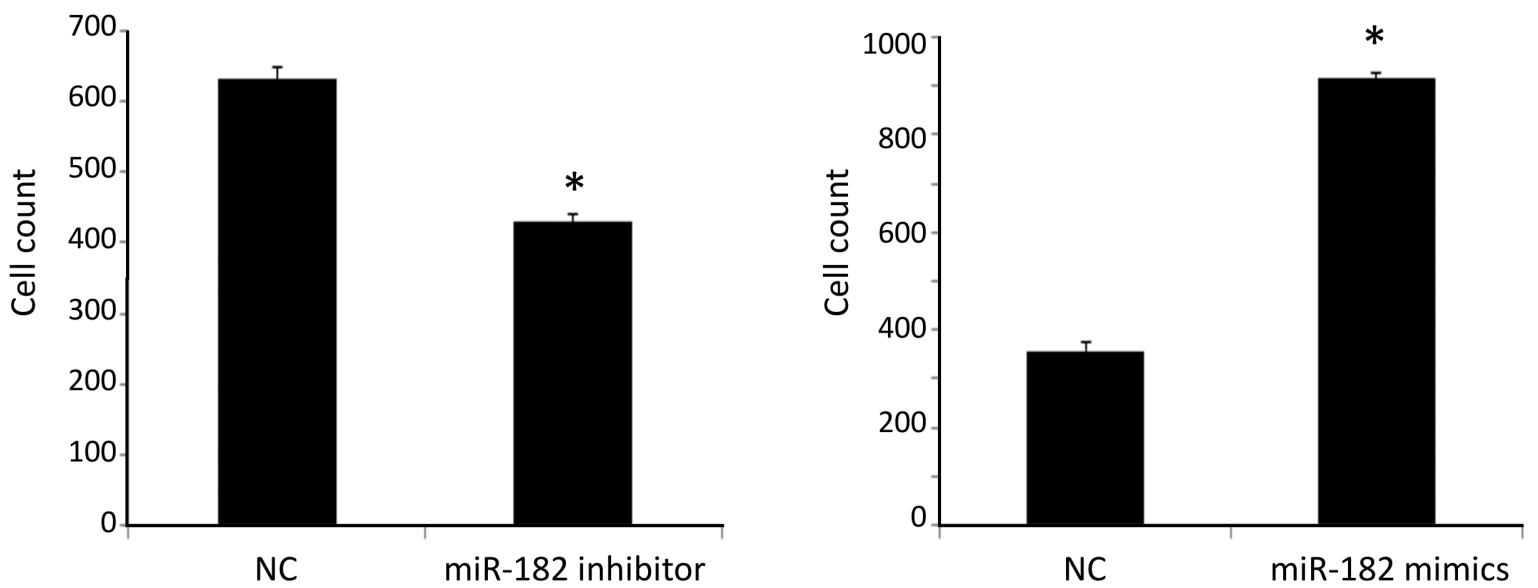

Figure 4. The cell migration of MCF7 cells and MDA-MB-231 cells after transfection with miR-182 mimics and miR-182 inhibitor, respectively. A, MCF7 cells; B, MDA-MB-231 cells. ${ }^{*}: \mathrm{P}<0.05,{ }^{* *}$ : $\mathrm{P}<0.01$. 


\section{Discussion}

TNBC is a clinically aggressive phenotype of breast cancer with poor prognosis and limited targeting therapies. Increasing evidence has highlighted the key role of miRNAs as diagnostic markers and therapeutic targets in tumor treatment [16]. In the present study, we found that miR-182 expression was significantly correlated with TNBC clinical indicators, such as lymph node metastasis TNM (stage III), intravascular cancer emboli and TNBC recurrence and metastasis. In addition, we found that miR-182 was up-regulated in TNBC tissues significantly. Also, miR-182 expression in MDA-MB-231 cells was significantly higher than that in MCF7 cells. Knockdown of miR-182 significantly inhibited the proliferation and migration of MDA-MB-231 cells while miR-182 overexpression markedly promoted these behaviors of MCF7 cells. Besides, FOXF2 was identified as a direct target of miR-182. All these findings imply the key role of miR-182 and merit further investigation.

Previous studies show that miR-182 is able to act as a tumor suppressor to control cell proliferation and invasion in lung cancer via targeting the regulator of the oncogene cortactin [17]. On the contrary, miR-182 is shown to downregulate metastasis suppressor 1 (MTSS1), thus promoting metastasis of hepatocellular carcinoma [18]. It is also reported that miR-182 overexpression contributes to cell proliferation and invasion in prostate cancer through suppressing NDRG1 [19]. Wang et al. also demonstrated that miR-182 could promote cell growth and invasion in human ovarian carcinomas [20]. In our study, miR-182 was markedly up-regulated in TNBC tissues. Also, knockdown of miR-182 significantly inhibited the proliferation and migration of MDA-MB-231 cells while miR-182 overexpression markedly promoted these behaviors of MCF7 cells. It can therefore speculate that knockdown of miR-182 may inhibit cell proliferation and migration in TNBC.

Furthermore, miR-182-5p is shown to promote cell proliferation and invasion in human prostate cancer via downregulating FOXF2 [21]. In this study, FOXF2 is also identified to be a direct and functional target of miR-182. FOXF2, a transcription factor, is shown to be involved in epithelial-mesenchymal interactions [22], which is associated with the metastatic capabilities of cancer cells [23]. Wang et al. also demonstrated that FOXF2 deficiency could promote epithelial-mesenchymal transition, thereby promoting the metastasis of basal-like breast cancer [24]. In addition, FOXF2, identified as a target of miR-301, functions as a crucial oncogene to mediate cell proliferation and invasion in breast cancer [25]. Besides, low levels of FOXF2 is demonstrated to predict shorter disease-free survival for those patients with TNBC [26]. Therefore, FOXF2 down-regulation may contribute to TNBC progression and is associated with poor prognosis. In our study, FOXF2 was identified as a direct target of miR-182, it could therefore be speculated that miR182 might promote cell proliferation and invasion in TNBC via targeting FOXF2.
However, we did not performed experiments, such as overexpression or knockdown of FOXF2, to verify whether FOXF2 dysregulation is associated with the malignant behaviors of TNBC cells. In addition, miR-182 is also proved to promote the tumor progression via targeting MTSS1 or NDRG1 [18, 19], implying that miR-182 may play a regulatory role in TNBC possible via suppressing other targets. Further studies are needed to investigate our observation.

\section{Conclusion}

In conclusion, our findings indicate that miR-182 may promote cell proliferation and migration in TNBC possible via down-regulation of FOXF2. miR-182 may serve as a potential target in the therapy of TNBC. Our findings will provide potential value for TNBC diagnosis and treatment.

Acknowledgements: This work was supported by Special fund for medical service of Jilin finance department (No.SCZSY201507)

\section{References}

[1] HUDIS CA, GIANNI L. Triple-negative breast cancer: an unmet medical need. Oncologist 2011; 16: 1-11. https://doi. org/10.1634/theoncologist.2011-S1-01

[2] SCHMADEKA R, HARMON BE, SINGH M. Triple-negative breast carcinoma. Am J Clin Pathol 2014; 141: 462-477. https://doi.org/10.1309/AJCPQN8GZ8SILKGN

[3] CLEATOR S, HELLER W, COOMBES RC. Triple-negative breast cancer: therapeutic options. Lancet Oncol 2007; 8: 235-244. https://doi.org/10.1016/S1470-2045(07)70074-8

[4] PODO F, BUYDENS LM, DEGANI H, HILHORST R, KLIPP E. et al. Triple-negative breast cancer: present challenges and new perspectives. Mol Oncol 2010; 4: 209-229. https://doi. org/10.1016/j.molonc.2010.04.006

[5] DP B. MicroRNAs genomics, biogenesis, mechanism, and function. Cell 2004; 116: 281-297.

[6] ESTELLER M. Non-coding RNAs in human disease. Nat Rev Genet 2011; 12: 861-874. https://doi.org/10.1038/nrg3074

[7] ESQUELA-KERSCHER A, SLACK FJ. Oncomirs- microRNAs with a role in cancer. Nat Rev Cancer 2006; 6: 259-269. https://doi.org/10.1038/nrc1840

[8] NICOLOSO MS, R. SHIMIZU, M. ROSSI, S. CALIN, GA. MicroRNAs-the micro steering wheel of tumour metastases. Nat Rev Cancer 2009; 9: 293-302. https://doi.org/10.1038/ $\underline{\operatorname{nrc2619}}$

[9] RADOJICIC J, ZARAVINOS A, VREKOUSSIS T, KAFOUSI M, SPANDIDOS DA. et al. MicroRNA expression analysis in triple-negative (ER, PR and Her2/neu) breast cancer. Cell Cycle 2011; 10: 507-517. https://doi.org/10.4161/ cc.10.3.14754

[10] KONG W, HE L, RICHARDS E, CHALLA S, XU C. et al. Upregulation of miRNA-155 promotes tumour angiogenesis by targeting VHL and is associated with poor prognosis and triple-negative breast cancer. Oncogene 2014; 33: 679-689. https://doi.org/10.1038/onc.2012.636 
[11] WANG C, ZHENG X, SHEN C, SHI Y. MicroRNA-203 suppresses cell proliferation and migration by targeting BIRC5 and LASP1 in human triple-negative breast cancer cells. J Exp Clin Cancer Res 2012; 31: 1. https://doi.org/10.1186/17569966-31-58

[12] SEGURA MF, HANNIFORD D, MENENDEZ S, REAVIE L, ZOU X. et al. Aberrant miR-182 expression promotes melanoma metastasis by repressing FOXO3 and microphthalmia-associated transcription factor. Proc Natl Acad Sci U S A 2009; 106: 1814-1819. https://doi.org/10.1073/pnas.0808263106

[13] JIANG L, MAO P, SONG L, WU J, HUANG J. et al. miR-182 as a prognostic marker for glioma progression and patient survival. Am J Pathol 2010; 177: 29-38. https://doi.org/10.2353/ ajpath.2010.090812

[14] SUN Y, FANG R, LI C, LI L, LI F. et al. Hsa-mir-182 suppresses lung tumorigenesis through down regulation of RGS17 expression in vitro. Biochem Biophys Res Commun 2010; 396: 501-507. https://doi.org/10.1016/j.bbrc.2010.04.127

[15] CHIANG C-H, HOU M-F, HUNG W-C. Up-regulation of miR-182 by $\beta$-catenin in breast cancer increases tumorigenicity and invasiveness by targeting the matrix metalloproteinase inhibitor RECK. Biochim Biophys Acta 2013; 1830: 30673076. https://doi.org/10.1016/j.bbagen.2013.01.009

[16] KASINSKI AL, SLACK FJ. MicroRNAs en route to the clinic: progress in validating and targeting microRNAs for cancer therapy. Nat Rev Cancer 2011; 11: 849-864. https://doi. org/10.1038/nrc3166

[17] ZHANG L, LIU T, HUANG Y, LIU J. microRNA-182 inhibits the proliferation and invasion of human lung adenocarcinoma cells through its effect on human cortical actin-associated protein. Int J Mol Med 2011; 28: 381-388.

[18] WANG J, LI J, SHEN J, WANG C, YANG L. et al. MicroRNA182 downregulates metastasis suppressor 1 and contributes to metastasis of hepatocellular carcinoma. BMC Cancer 2012; 12: 1. https://doi.org/10.1186/1471-2407-12-227

[19] LIU R, LI J, TENG Z, ZHANG Z, XU Y. Overexpressed microRNA-182 promotes proliferation and invasion in pros- tate cancer PC-3 cells by down-regulating N-myc downstream regulated gene 1 (NDRG1). PloS One 2013; 8: e68982. https:// doi.org/10.1371/journal.pone.0068982

[20] WANG YQ, GUO RD, GUO RM, SHENG W, YIN LR. MicroRNA-182 promotes cell growth, invasion, and chemoresistance by targeting programmed cell death 4 (PDCD4) in human ovarian carcinomas. J Cell Biochem 2013; 114: 1464-1473. https://doi.org/10.1002/jcb.24488

[21] HIRATA H, UENO K, SHAHRYARI V, DENG G, TANAKA Y. et al. MicroRNA-182-5p promotes cell invasion and proliferation by down regulating FOXF2, RECK and MTSS1 genes in human prostate cancer. PloS One 2013; 8: e55502. https:// doi.org/10.1371/journal.pone.0055502

[22] AITOLA M, CARLSSON P, MAHLAPUU M, ENERBÄCK S, PELTO-HUIKKO M. Forkhead transcription factor FoxF2 is expressed in mesodermal tissues involved in epithelio-mesenchymal interactions. Dev Dyn 2000; 218: 136-149. https:// doi.org/10.1002/(SICI) 1097-0177(200005)218:1<136::AIDDVDY12>3.0.CO;2-U

[23] TSE JC, KALLURI R. Mechanisms of metastasis: epithelialto-mesenchymal transition and contribution of tumor microenvironment. J Cell Biochem 2007; 101: 816-829. https://doi.org/10.1002/jcb.21215

[24] WANG Q-S, KONG P-Z, LI X-Q, YANG F, FENG Y-M. FOXF2 deficiency promotes epithelial-mesenchymal transition and metastasis of basal-like breast cancer. Breast Cancer Res 2015; 17: 30. https://doi.org/10.1186/s13058015-0531-1

[25] SHI W, GERSTER K, ALAJEZ NM, TSANG J, WALDRON L. et al. MicroRNA-301 mediates proliferation and invasion in human breast cancer. Cancer Res 2011; 71: 2926-2937. https:// doi.org/10.1158/0008-5472.CAN-10-3369

[26] KONG P-Z, YANG F, LI L, LI X-Q, FENG Y-M. Decreased FOXF2 mRNA expression indicates early-onset metastasis and poor prognosis for breast cancer patients with histological grade II tumor. PloS One 2012; 8: e61591-e61591. https://doi. org/10.1371/journal.pone.0061591 